\title{
Peak-shaving-constraint based assessment methods of wind power integration capacity of regional power grids considering multiple factors
}

\author{
C.Z. Tian, S.Q. Wang, Y.B. Mao \\ State Grid Henan Economic Research Institute \\ Zhengzhou, China
}

\begin{abstract}
Currently, research on wind power integration capacity based on peak load regulation constraint is mainly aimed at provincial power grids. Regional and provincial power grids are quite different, and wind power integration capacity of provincial grids is of little reference value for regional wind power planning. In this paper, According to the basic principles of wind power capacity assessment, the maximum output factor under certain probability is taken as the regional wind power output coefficient. Then, the assessment method of wind power capacity is proposed for receiving-end and sending-end power grids, considering the interregional tie-line power adjustment and unit maintenance. Finally, the wind power integration capacity of a regional power grid is assessed as an example to prove the validity of the proposed method.

Keywords- wind power integration capacity; regional power grid; peak load regulation constraint; tie-line power adjustment; unit maintenance.
\end{abstract}

\section{INTRODUCTION}

The most important factor limiting wind power integration capacity is system peak load regulation capacity [1-2]. Currently, research on wind power integration capacity based on peak load regulation constraints is mainly aimed at provincial power grids [34]. Regional power grids are different from provincial power grids in the following aspects. 1) When calculating the wind power acceptance capacity of a provincial grid, the minimum conventional power output is expressed as a comprehensive coefficient. For the regional power grid, it is necessary to precisely consider the peak load regulation capacity of various power sources. 2) For a provincial power grid, its power exchange with surrounding provinces through tie-lines is restricted and is generally assumed to be constant. For a regional power grid, the tie-line power between the adjacent regions of a province is relatively flexible. 3 ) For a provincial power grid, the maintenance reserve is considered as a coefficient; for a regional power grid, regional power unit of the maximum capacity is considered for maintenance.

In this paper, an assessment method of wind power integration capacity of regional power grids is proposed based on peak-shaving constraints. Firstly, the way to get the regional wind power output coefficient which is

\author{
L.Y. Li
}

State Key Laboratory of Alternate Electrical Power System with Renewable Energy Sources NCEPU, Beijing, China.

to be used is given. Secondly, based on the peak-shaving constraint, considering interregional tie-line power adjustment factor, the largest unit maintenance and other factors, the assessment method of different types of regional power grids' wind power acceptance capacity is studied. Finally, a regional power grid is taken as an example to validate the feasibility of the proposed method.

\section{AN ASSESSMENT METHOD OF WIND POWER INTEGRATION CAPACITY OF REGIONAL POWER GRIDS}

\section{A. Basic principles}

The effects of wind power output on load curve can be classified as "anti-peak-shaving", "help-peak-shaving" and "excessive peak shaving" [5-7].

As a matter of fact, wind power usually plays a role as "anti-peak-shaving". "anti-peak-shaving" means the peak valley load difference of equivalent load (the original load minus wind power output) is larger with respect to that of the original load, increasing the difficulty of system peak-shaving.

The most critical "anti-peak-shaving" condition is considered when evaluating the wind power integration capacity. Vast statistics of wind power output indicates that the probability of wind power output during peak load period below $10 \%$ is high [8-9]. So the wind power output at peak load is supposed to be 0 , the maximum wind power output can be got through power balance at valley load moment, and the maximum wind installed capacity equals the maximum accepted wind power divide the wind output coefficient [10].

\section{B. Determination of the wind power output coefficient}

Usually, the regional wind power output coefficient can be express as the simultaneity factor, as (1).

$$
\rho=\frac{P_{w \max }}{S_{\text {wind }}}
$$

In (1), $P_{w \max }$ is the maximum wind power output of a region, $S_{\text {wind }}$ is the wind power installed capacity. 
However, there is shortage about the equation above. There is very low probability that the wind power output reaches maximum, the calculation result is conservative. If the wind power output reaches the highest value at the peak load moment, the simultaneity factor does not reflect the anti-peaking characteristics, the result is not correct.

Maximum output factor of regional representational wind farms under certain probability during valley load period is taken as the regional wind power output coefficient, as (2).

$$
P\left\{P_{t} \leq \eta\right\} \geq \alpha, \quad t \in T_{\text {valley }}
$$

In (2), $P_{t}$ is the ratio of wind power output and wind installed capacity, $\eta$ is the wind power output coefficient, $\alpha$ is the cumulative probability value from small to large, ${ }^{t}$ is the time , $T_{\text {valley }}$ is the valley load period.

\section{Wind power integration capacity assessment for different types of regional power grids}

Tie-line power between adjacent regional grids has a great influence on the wind power integration capacity. The tie-line power at the time of peak load can be obtain through power balance, as shown in (3).

$$
\begin{gathered}
P_{t h}=\mathrm{P}_{G}-P_{l \text { max }} \\
P_{G}=\mathrm{P}_{G M}-P_{r e}
\end{gathered}
$$

In (3), $P_{\text {th }}$ is the tie line power at peak load moment (suppose the out sending direction is positive), $P_{l \max }$ is the peak value of load, $P_{G}$ is the power supply capacity of a regional power grid without considering the electricity network losses and auxiliary power. In (4), $P_{G M}$ is the maximum output power of all power units in a region which minus the largest capacity of units when considering maintenance reserve, $P_{r e}$ is the spinning reserve capacity.

According to the value of $P_{\text {th }}$, the regional power grid is classified as receiving-end, sending-end, or relative power-balance grids.

1) Wind power integration capacity assessment of receiving-end regional power grids

Maximum accepted wind power can be calculated as shown in Fig .1.

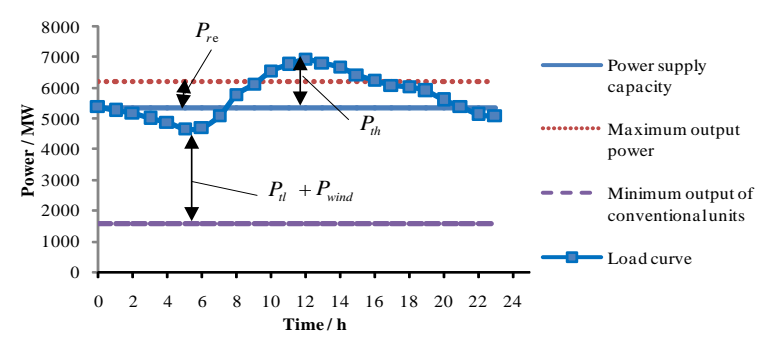

Figure 1. The schematic diagram of maximum accepted wind power calculation for receiving-end regional power grid

For receiving-end regional power grid, the power source of valley load consists of three parts: the minimum output of conventional units, the maximum accepted wind power and interregional tie-line power, thus maximum accepted wind power is calculated in (5).

$$
\mathrm{P}_{\text {wind }}=\lambda P_{l \max }+P_{t l}-\left(\beta_{1} P_{G 1}+\beta_{2} P_{G 2}+\mathrm{L}\right)
$$

In (5), $P_{\text {wind }}$ is the maximum accepted wind power, $\lambda$ minimum daily load factor, $P_{t l}$ is the tie-line power at valley load moment, $\mathrm{P}_{t l}=r \mathrm{P}_{t h}, r$ is the tie-line power adjustment factor considering maximum power transferring capability, $\beta_{1} 、 \beta_{2}$ is the minimum output rates of different types of units, $P_{G 1} 、 P_{G 2}$ is installed capacity of different types of units.

The tie-line power adjustment means that the neighbouring regional power grids are involved in peakshaving. The final accepted wind power for regional power grid is

$$
\mathrm{P}_{\text {wind }}= \begin{cases}P_{\text {wind }}, & P_{\text {wind }} \leq P_{\text {wind }}^{\prime} \\ P_{\text {wind }}^{\prime}, & P_{\text {wind }}>P_{\text {wind }}^{\prime}\end{cases}
$$

In (6), $P_{\text {wind }}^{\prime}$ is the overall accepted wind power of the concerned region and its neighbouring regions which is calculated excluding the tie-line power adjustment of those regions as a whole.

The maximum capacity of wind power to accept is calculate as (7)

$$
S_{\text {wind }}=\mathrm{P}_{\text {wind }} / \eta
$$

2) Wind power integration capacity assessment of sending-end regional power grid

Maximum accepted wind power can be calculated as shown in Fig .2. 


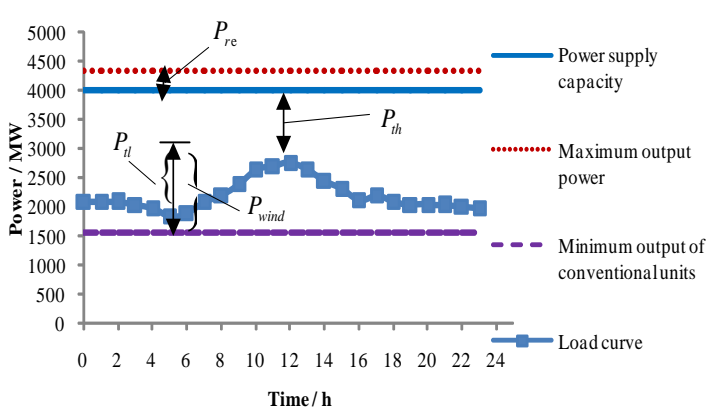

Figure 2. The schematic diagram of maximum accepted wind power calculation for sending-end regional power grid

As shown is Fig .2, unlike the receiving-end grid, the maximum accepted wind power equals the valley load pluses the output power of a region (tie-line power), then minuses the minimum output of conventional units. For sending-end regional power grid, particular attention should be paid to the tie-line power not exceeding the transmission limits.

For the relative power-balance regional power grid, the way to obtain maximum wind power integration capacity is approximate.

\section{CASE STUDY}

\section{A. Calculation conditions}

In this paper, an actual regional power grid is selected to assess its acceptance of wind power capacity. The calculation conditions are as following. Because the peak valley load difference is large in summer days, while the peak-shaving capacity of heating cogeneration units is poor and wind power output is higher in winter days, the wind power integration capacity in these two seasons is less. The wind power capacity needs to be calculated separately in winter and summer.

Select two typical wind farms which can represent the wind power output characteristics of the region. Take $90 \%$ as a relative higher value of cumulative probability, Wind power output coefficients in winter and summer days are 0.60 and 0.40 respectively.

\section{B. Wind power integration capacity assessment}

The statistics data of load and power units of the regional power grid are collected for 2015-2020. The tie-line power is calculated at peak load. The results show that the regional power grid is a receiving-end grid in 2015-2020. For receiving-end power grid, the influence of unit maintenance on the wind power integration capacity includes two aspects: 1) enlarge the electric power from other regions, thus reducing the acceptable wind power; 2) reduce the minimum conventional power output, thereby increasing the wind power to accept.

Conventional thermal power units have the largest capacity. When the tie-line power adjustment factor is between $100 \%$ to $50 \%$, the wind power to accept is less when considering unit maintenance than without considering; when the factor is $50 \%$, the result is the same; when the factor is less than $50 \%$, the wind power integration capacity is larger when considering unit maintenance.
Based on the above analysis, whether considering unit maintenance or not is taken into account so that the wind power integration capacity is least as shown in Fig .3. In Fig .3, the points facing the year represent summer; the points between adjacent years represent winter.

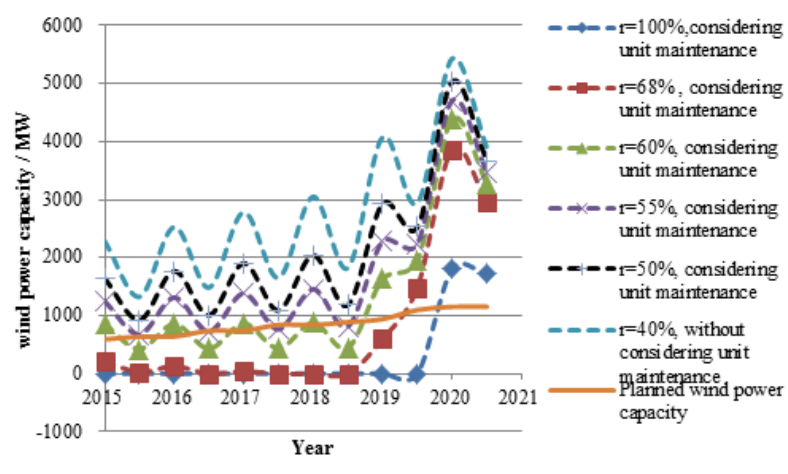

Figure 3. Maximum wind power integration capacity in 2015-2020

As can be seen from Fig .3, from 2015 to 2019, the load in the region grows, the peak valley load difference increases, while the power capacity is essentially the same, the interregional grid tie-line power adjustment factor should be in the range of $60 \%$ to $55 \%$ to meet the planned total wind power capacity. At the same time, the maximum wind integration capacity in winter is less than that in summer. In 2020, due to the new built pumped storage power plants and the operation of thermal power units of large capacity which have more peak-shaving capacity, the wind power acceptance capacity has been greatly improved, and the tie-line power adjustment factor is more flexible. At the same time, due to those units above are put into operation in winter, the wind power integration capacity in winter is larger than in summer.

TABLE I. WIND POWER INTEGRATION CAPACITY OF THE STUDIED GRID AND ITS SENDING-END REGIONAL POWER GRIDS (MW)

\begin{tabular}{|c|c|c|c|}
\hline \multicolumn{2}{|c|}{} & $\begin{array}{c}\text { planned } \\
\text { wind } \\
\text { power } \\
\text { capacity }\end{array}$ & $\begin{array}{c}\text { wind power } \\
\text { integration capacity } \\
\text { of the related } \\
\text { regional grids }\end{array}$ \\
\hline \multirow{2}{*}{2015} & s & 591 & 2000 \\
\cline { 2 - 4 } & w & 641 & 2101 \\
\hline \multirow{2}{*}{2016} & s & 641 & 2311 \\
\cline { 2 - 4 } & W & 741 & 2350 \\
\hline \multirow{2}{*}{2017} & s & 741 & 2700 \\
\cline { 2 - 4 } & w & 841 & 2750 \\
\hline \multirow{2}{*}{2018} & s & 841 & 2880 \\
\cline { 2 - 4 } & w & 890 & 2912 \\
\hline \multirow{2}{*}{2019} & s & 941 & 2932 \\
\cline { 2 - 4 } & W & 1100 & 3200 \\
\hline \multirow{2}{*}{2020} & s & 1153 & 4700 \\
\cline { 2 - 4 } & w & 1153 & 5032 \\
\hline
\end{tabular}

annotation: S represents summer, $w$ winter. 
Since the Tie-line power adjustment is essentially passing the peak-shaving problem to the neighbouring regions. Take the studied region and its sending-end regional power grids as a whole, its wind power capacity to accept is listed in TABLE I.

The results show that the studied regional power grid can accept the planned wind power capacity considering peak load regulation constraints.

\section{CONCLUSION}

In this paper, the maximum output factor of regional representational wind farms under certain probability during the valley load period is taken as the regional wind power output coefficient, which can reflect the "anti-peak-shaving" characteristics better. Considering the most serious "anti-peak-shaving" case, the tie-line power at the peak load moment can be got through power balance. The maximum accepted wind power is calculated considering unit maintenance, tie-line power adjustment, the minimum output of various conventional units. The proposed method can calculate the regional wind power integration capacity more accurately to better provide a reference for regional wind power planning.

\section{REFERENCES}

[1] Xiaoqi Han, Shouguang Sun, Qingru Qi. Evaluation of wind power penetration limit from peak regulation [J]. Electric power, 2010, 06: 16-19.
[2] Fang fang, Niu dongxiao, Lu yan. The study on power system load regulation capacity economic analysis [J]. Advances in Information Sciences and Service Sciences, 2012, 4(1): 77-84.

[3] Dezhi Chen, Gonggao Wu. Impact of grid-connected large-scale wind power on peak load regulation in Shanxi grid $[\mathrm{J}]$. East China Electric Power, 2011, 39(8): 1257-1261.

[4] Wu Gonggao, Ye Zhongxiong, Yao Ming, et al.. Capacity Analysis on wind power integration into Anhui power grid [J]. East China Electric Power, 2011, 39(6): 997-999.

[5] Qiyu Chen, Littler T., Jiang Wenling, et al.. Offshore wind power impact on peak load regulation of power systems[C]. IEEE PES General Meeting 2014, vol. 1, no. 5, pp. 27-31.

[6] Bo Yuan, Ming Zhou, Jin Zong. An overview on peak regulation of wind power integrated power systems [C]. 4th International Conference on Electric Utility Deregulation and Restructuring and Power Technologies (DRPT), 2011: 145-150.

[7] Zhang Ning, Zhou Tianrui, Duan Changgang, et al.. Impact of large-scale wind farm connecting with power grid on peak load regulation demand $[\mathrm{J}]$. Power System Technology, 2010, 34(1): 52-58.

[8] Xiuyuan Yang, yang Xiao, Shuyong. Chen, Wind speed and generated power forecasting in wind farm $[\mathrm{J}]$. Proceedings of the CSEE, 2005, 11: 1-5.

[9] SUN Rongfu, ZHANGTao, LIANG Ji. Evaluation and application of wind power integration capacity inpower grid[J]. Automation of Electric Power System, 2011, 35(4) : 70-76.

[10] Wang Zhiming, Su Anlong, Lu Shun. Analysis on capacity of wind power integrated into Liaoning power grid based on power balance [J]. Automation of Electric Power Systems, 2010, 34(3): 86-90. 